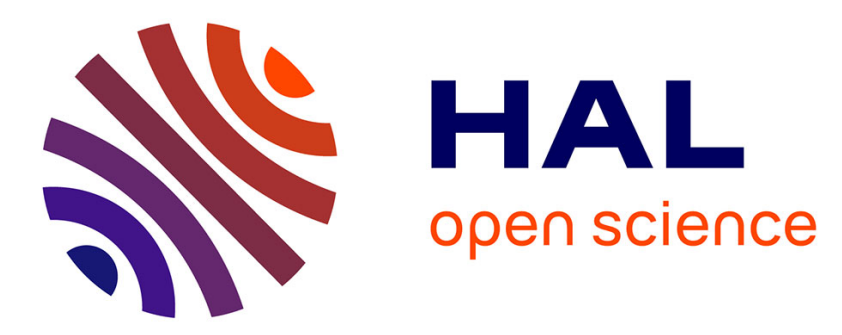

\title{
Spectroscopic and structural investigation of undoped and Er3+ doped hafnium silicate layers.
}

Larysa Khomenkova, Yong Tao An, Dimitri Khomenkov, Xavier Portier, Christophe Labbé, Fabrice Gourbilleau

\section{- To cite this version:}

Larysa Khomenkova, Yong Tao An, Dimitri Khomenkov, Xavier Portier, Christophe Labbé, et al.. Spectroscopic and structural investigation of undoped and Er3+ doped hafnium silicate layers.. Physica B: Condensed Matter, 2014, 453, pp.100-106. 10.1016/j.physb.2014.03.087 . hal-01078069

\section{HAL Id: hal-01078069 \\ https://hal.science/hal-01078069}

Submitted on 26 Jun 2018

HAL is a multi-disciplinary open access archive for the deposit and dissemination of scientific research documents, whether they are published or not. The documents may come from teaching and research institutions in France or abroad, or from public or private research centers.
L'archive ouverte pluridisciplinaire HAL, est destinée au dépôt et à la diffusion de documents scientifiques de niveau recherche, publiés ou non, émanant des établissements d'enseignement et de recherche français ou étrangers, des laboratoires publics ou privés. 


\title{
Spectroscopic and structural investigation of undoped and $\mathrm{Er}^{3+}$ doped hafnium silicate layers
}

\author{
L. Khomenkova ${ }^{\text {a,b,*, }}$ Y.-T. An ${ }^{\text {a }}$, D. Khomenkov ${ }^{c}$, X. Portier ${ }^{\text {a }}$, C. Labbé ${ }^{\mathrm{a}}$, F. Gourbilleau ${ }^{\mathrm{a}}$ \\ ${ }^{a}$ CIMAP CEA/CNRS/ENSICAEN/UCBN, 6 Blvd. Maréchal Juin, 14050 Caen Cedex 4, France \\ ${ }^{\mathrm{b}} \mathrm{V}$. Lashkaryov Institute of Semiconductor Physics at NASU, 41 Pr. Nauky, Kyiv 03028, Ukraine \\ ${ }^{\mathrm{c}}$ Taras Shevchenko National University of Kyiv, Faculty of Physics, 4 Pr. Hlushkov, Kyiv 03022, Ukraine
}

Keywords:

Hafnium silicate films,

Erbium,

Photoluminescence, TEM,

Raman scattering, FTIR.

\begin{abstract}
A B S T R A C T
This paper demonstrates the functionality of radio-frequency magnetron sputtering for the fabrication of undoped and Er-doped Si-rich- $\mathrm{HfO}_{2}$ films with specific structural and spectroscopic properties. The effect of post-deposition treatment on film properties was investigated by means of Fourier-transform infrared spectroscopy, Raman scattering and photoluminescence methods, as well as Transmission Electron microscopy. It was observed that annealing treatment at $850-1000{ }^{\circ} \mathrm{C}$ causes phase separation process and the formation of $\mathrm{HfO}_{2}, \mathrm{SiO}_{2}$ and pure $\mathrm{Si}$ phases. This process stimulates also an intense light emission in the 700-950-nm spectral range under broad band excitation. The phase separation mechanism as well as the nature of radiative transitions were discussed. Photoluminescence was ascribed to carrier recombination in silicon clusters and host defects. The appearance of silicon clusters was also confirmed by the comparison of luminescent properties of pure $\mathrm{HfO}_{2}$, $\mathrm{SiO}$, Si-rich- $\mathrm{HfO}_{2}$ and $\mathrm{Si}$ rich- $\mathrm{SiO}_{2}$ films. Additional argument for Si clusters' formation was obtained under investigation of Erdoped Si-rich $\mathrm{HfO}_{2}$ films. These latter demonstrated $1.54-\mu \mathrm{m} \mathrm{Er}{ }^{3+}$ luminescence under non-resonant excitation originating from an energy transfer from Si clusters towards $\mathrm{Er}^{3+}$ ions.
\end{abstract}

\section{Introduction}

Hafnia-based materials are mainly considered as alternative dielectrics to $\mathrm{SiO}_{2}$ in Si-based CMOS technology [1-3]. Along with promising electrical properties, $\mathrm{HfO}_{2}$ has a high optical transparency in the ultraviolet-infrared spectral range, high refractive index (2.0-2.1 at $1.95 \mathrm{eV})$, wide optical bandgap $(\sim 5.8 \mathrm{eV})$ and low phonon cut-off energy $\left(\sim 780 \mathrm{~cm}^{-1}\right)$ offering a low probability of phonon assisted relaxation. Despite these advantages, spectroscopic investigation and optical applications of $\mathrm{HfO}_{2}$-based materials are not numerous $[4,5]$.

Intrinsic luminescence of pure $\mathrm{HfO}_{2}$ is usually observed at 4.2$4.4 \mathrm{eV}$ and ascribed to self-trapped exciton [6,7], whereas visible emission (2.5-3.5 eV) is attributed to different oxygen vacancies with trapped electrons [6]. An emission of $\mathrm{HfO}_{2}$ materials doped with rare-earth elements was also demonstrated [8,9], but the mechanism of the excitation of rare-earth ions and their interaction with the host defects were not clarified.

\footnotetext{
* Corresponding author at: V. Lashkaryov Institute of Semiconductor Physics at NASU, 41 Pr. Nauky, Kyiv 03028, Ukraine.

E-mail addresses: khomen@ukr.net, khomen@isp.kiev.ua (L. Khomenkova).
}

The development of rare-earth doped materials suffers from their lower absorption cross-sections for $4 \mathrm{f}-4 \mathrm{f}$ transitions $\left(10^{-18}\right.$ $\left.10^{-20} \mathrm{~cm}^{-2}\right)$ and requires high-power excitation sources. Meanwhile, $4 \mathrm{f}-5 \mathrm{~d}$ transitions have higher cross-section $\left(\sim 10^{-12} \mathrm{~cm}^{-2}\right)$, but corresponding excitation levels belong to UV and vacuum UV spectral range, restricting many applications of these materials. Thus, to enhance an excitation of $4 \mathrm{f}-4 \mathrm{f}$ transitions, a host mediated excitation via energy transfer is needed.

Trivalent erbium ion $\left(\mathrm{Er}^{3+}\right)$ is one of the most popular lanthanides due to its radiative transitions in the green $\left({ }^{4} \mathrm{~S}_{3 / 2} \rightarrow\right.$ $\left.{ }^{4} \mathrm{I}_{15 / 2}, 558 \mathrm{~nm}\right)$ and in the infrared $\left({ }^{4} \mathrm{I}_{13 / 2} \rightarrow{ }^{4} \mathrm{I}_{15 / 2}, 1.54 \mu \mathrm{m}\right)$ being extensively used as an eye-safe source in atmosphere, laser radar, medicine and surgery $\left({ }^{4} \mathrm{I}_{11 / 2} \rightarrow{ }^{4} \mathrm{I}_{13 / 2}\right)[10,11]$. Earlier, a lot of efforts have been concentrated on $\mathrm{Er}^{3+}$-doped $\mathrm{Si}$-rich-SiO $\mathrm{S}_{2}$ materials [1214]. An enhancement of $\mathrm{Er}^{3+}$ absorption cross-section from $10^{-21} \mathrm{~cm}^{-2}$ [15] up to $10^{-16} \mathrm{~cm}^{-2}[13,14]$ was achieved due to an effective energy transfer from Si-nanoclusters (Si-ncs) towards $\mathrm{Er}^{3+}$ ions under visible broad-band excitation. Only a few studies of Er-doped $\mathrm{SiO}_{2}-\mathrm{HfO}_{2}$ materials were reported [8,16,17], whereas $\mathrm{Er}^{3+}$ ion excitation mechanism was not considered well.

In this work we present the results of a spectroscopic investigation of different $\mathrm{HfO}_{2}$-based materials, i.e. pure and Si-rich $\mathrm{HfO}_{2}$ materials (either undoped or doped with $\mathrm{Er}^{3+}$ ions). The effect of annealing treatment on the formation of Si-ncs in Si-rich $\mathrm{HfO}_{2}$ 
host as well as the interaction mechanism of Si-ncs, $\mathrm{Er}^{3+}$ ions and host defects are investigated to achieve and to control light emitting properties of these materials.

\section{Experimental details}

The layers investigated were grown RF magnetron sputtering of pure $\mathrm{HfO}_{2}$ target (99.9\%) topped by calibrated $\mathrm{Si}$ and/or $\mathrm{Er}_{2} \mathrm{O}_{3}$ chips on pure $\mathrm{Si}$ and fused quarts substrates. Both types of substrates were placed on the same sample holder to obtain the layers grown at the same conditions. Before deposition, all Si wafers were etched in $10 \%$-water $\mathrm{HF}$ solution to remove thermal $\mathrm{SiO}_{2}$ layer from their surface. Substrate temperature was kept at $100{ }^{\circ} \mathrm{C}$. The films were deposited in pure argon plasma with RF power density of $0.74 \mathrm{~W} / \mathrm{cm}^{2}$ during $200 \mathrm{~min}$. The thickness of all films investigated was about $850 \mathrm{~nm}$. After deposition, the wafers were cut on $1 \times 1 \mathrm{~cm}^{2}$ pieces. Thermal treatments of the samples were performed in a conventional furnace in nitrogen flow at $T_{A}=800-$ $1100{ }^{\circ} \mathrm{C}$ and $t_{A}=10-60$ min. Besides, pure and Si-rich $\mathrm{SiO}_{2}$ films were grown by similar approach from a pure $\mathrm{SiO}_{2}$ target $(99.99 \%)$ and processed with the same conditions. More experimental details can be found in Ref. [3]. This allowed a comparative investigation of Si-ncs formation in Si-rich $\mathrm{HfO}_{2}$ films and Sirich-SiO ${ }_{2}$ films to be performed.

The microstructure of the layers was analyzed by means of Fourier-transform infrared (FTIR) spectroscopy. The spectra were recorded in the range of $600-4000 \mathrm{~cm}^{-1}$ using a Nicolet Nexus spectrometer under normal and Brewster angle $\left(65^{\circ}\right)$ configuration. Raman scattering spectra were investigated with backscattered geometry using a dispersive Raman spectrometer equipped with a CCD camera and a laser source at $532 \mathrm{~nm}$. Transmission electron microscopy (TEM) was used to observe the evolution of the film structure with annealing. Photoluminescence (PL) and PL excitation (PLE) spectra in the 200-800 nm

a

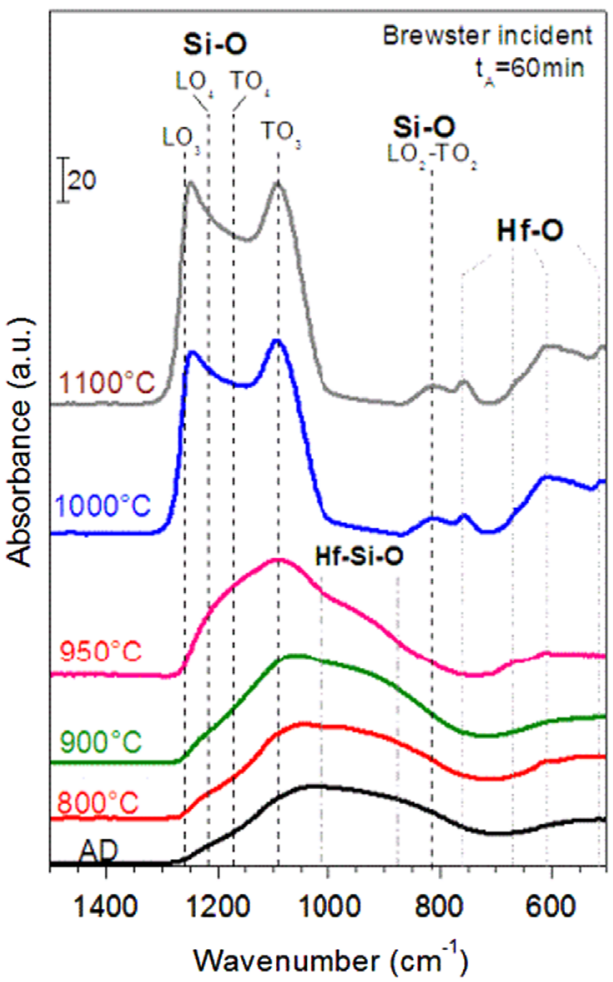

spectral range were studied with a Jobin-Yvon Fluorolog3-22 setup equipped with a Xe lamp as excitation source and a R928 photomultiplayer tube. All measurements were performed at room temperature.

\section{Results and discussion}

\subsection{Microstructure of the samples versus annealing treatment}

FTIR and Raman scattering spectra we measured to study the microstructure evolution of the films with thermal treatment. Both methods allowed following the phase separation process upon annealing.

Fig. 1 represents the FTIR spectra obtained for as-deposited (AD) and annealed samples. AD samples show two broad bands (Fig. $1 \mathrm{a}$ and $\mathrm{b}$ ). One of them, detected in the range of the 500$700 \mathrm{~cm}^{-1}$, is caused by Hf-O vibrations [18-25]. Usually, amorphous films show a broad Hf-O vibration band [18-20,25], whereas their crystalline counterparts demonstrate the peaks at $760-780 \mathrm{~cm}^{-1}, 640-670 \mathrm{~cm}^{-1}$ and $500-560 \mathrm{~cm}^{-1}$ [20,23-25]. Precise spectral positions and corresponding intensities of these bands depend on the $\mathrm{HfO}_{2}$ crystalline nature (monoclinic, tetragonal, orthorhombic or cubic) [24,25].

Another vibration band, observed for AD films, locates at $\sim 1010-1030 \mathrm{~cm}^{-1}$ (Fig. 1a) and $940-960 \mathrm{~cm}^{-1}$ (Fig. 1b). It can be ascribed to $\mathrm{Hf}-\mathrm{Si}-\mathrm{O}$ stretching vibration mode taking into account the transformation of FTIR spectra of pure $\mathrm{HfO}_{2}$ films with $\mathrm{Si}$ incorporation towards $\mathrm{HfSiO}_{x}$ host formation $[2,20,27]$.

Thermal treatment at $T_{A}=800-950{ }^{\circ} \mathrm{C}$ and $t_{A}=60 \mathrm{~min}$ causes an increase of the intensity of $\mathrm{O}-\mathrm{Si}-\mathrm{Hf}$ band and its spectral shift up to $1070-1080 \mathrm{~cm}^{-1}$, while $\mathrm{Hf}-\mathrm{O}$ vibration band remains unchanged (Fig. 1a and b). FTIR spectra of the films annealed at $T_{A}=1000{ }^{\circ} \mathrm{C}$ and $t_{A}=60 \mathrm{~min}$ show several peaks at about $670 \mathrm{~cm}^{-1}$ and $760 \mathrm{~cm}^{-1}$ (Fig. 1a) and $560 \mathrm{~cm}^{-1}, 650 \mathrm{~cm}^{-1}$ and

b

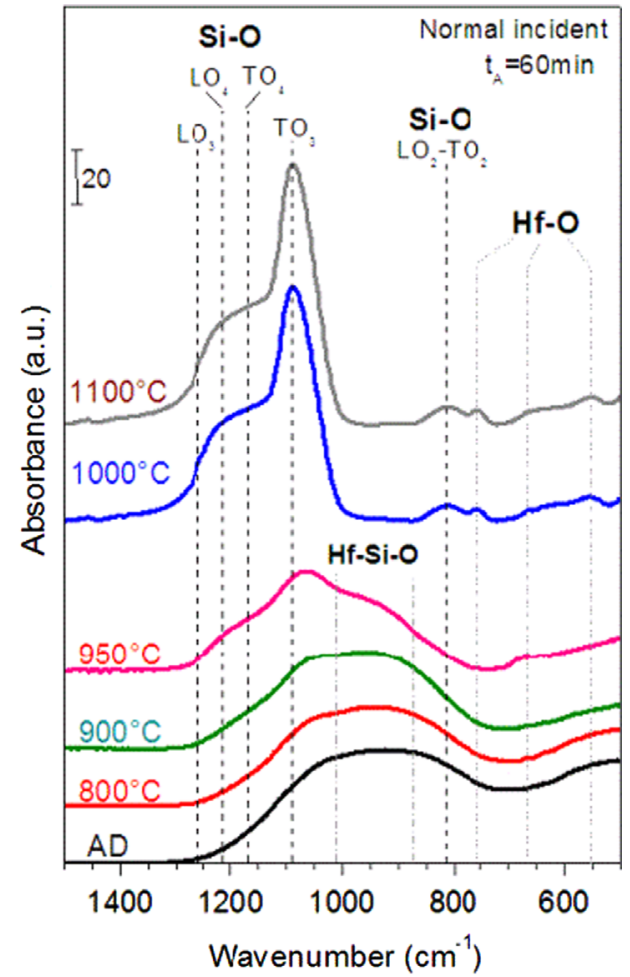

Fig. 1. Evolution of FTIR spectra of Si-rich- $\mathrm{HfO}_{2}$ films with $T_{A}$. Spectra were measured at Brewster $\left(65^{\circ}\right)$ (a) and normal incident (b) of the light. Annealing time is $t_{A}=60$ min. 
a

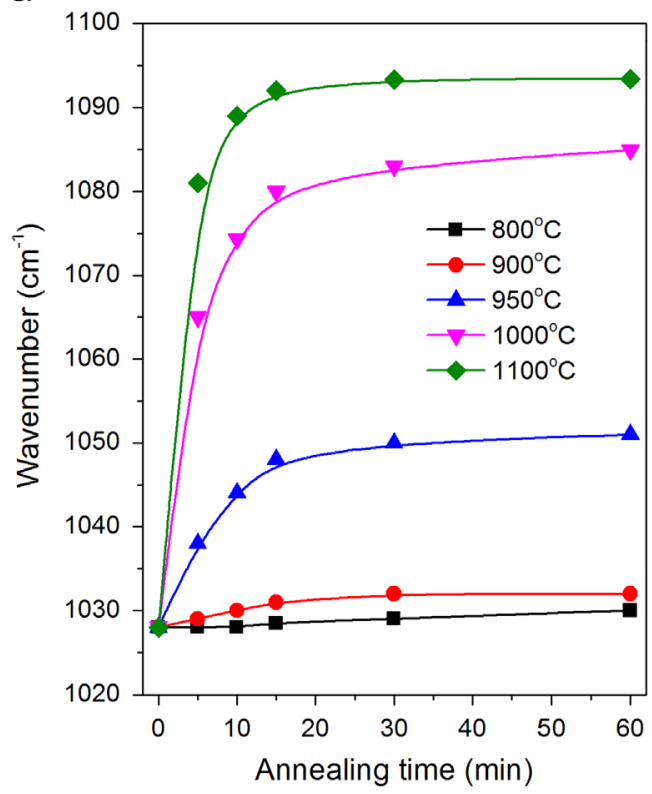

b

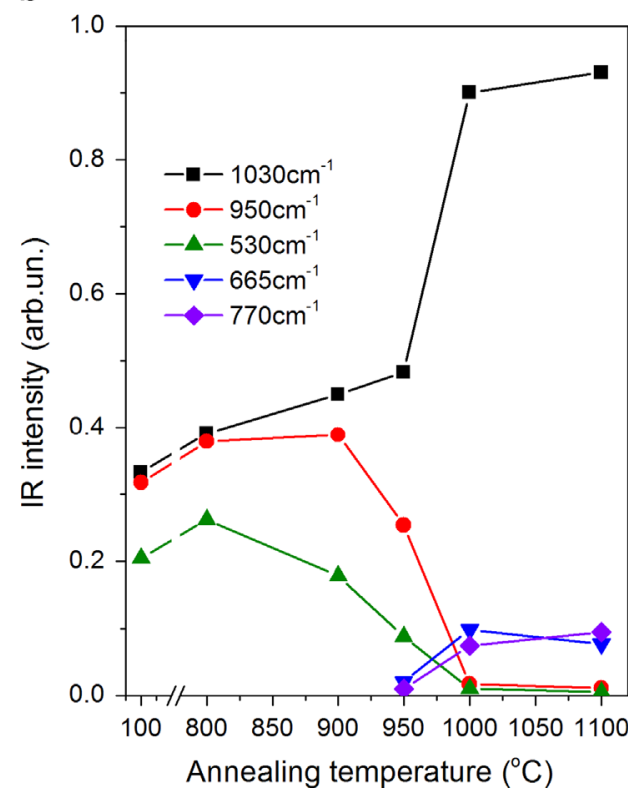

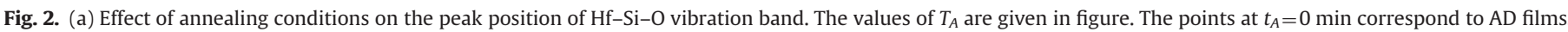

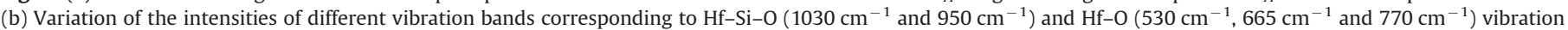
bands with $T_{A} ; t_{A}=60 \mathrm{~min}$. The points at $T_{A}=100{ }^{\circ} \mathrm{C}$ correspond to $\mathrm{AD}$ films. Analysis was performed on FTIR spectra measured at Brewster $\left(65^{\circ}\right)$ incidence.

$760 \mathrm{~cm}^{-1}$ (Fig. 1b) that are due to Hf-O vibrations [20,24-27]. Besides, the bands centered at $820 \mathrm{~cm}^{-1}, 1090 \mathrm{~cm}^{-1}$ and $1250 \mathrm{~cm}^{-1}$ (Fig. 1a) and at $820 \mathrm{~cm}^{-1}, 1085 \mathrm{~cm}^{-1}$ and $1210 \mathrm{~cm}^{-1}$ (Fig. 1b) are also observed. They can be explained by the different optical $\mathrm{SiO}_{2}$ phonons $[2,28,29]$. This evolution of FTIR spectra can be caused by a phase separation process leading to the formation of $\mathrm{SiO}_{x}$ and $\mathrm{HfO}_{x}$ phases. However, the shoulder at about $950 \mathrm{~cm}^{-1}$ could be an evidence of the presence of $\mathrm{HfSiO}_{x}$ phase in the films annealed at $T_{A}<1000{ }^{\circ} \mathrm{C}$, meaning that the phase separation is not complete. An annealing at $T_{A}=1100{ }^{\circ} \mathrm{C}$ and $t_{A}=60 \mathrm{~min}$ results in the narrowing of all vibration bands as well as in the disappearance of the shoulder at $950 \mathrm{~cm}^{-1}$ that reflects a complete phase separation process (Fig. 1).

The effect of the duration of annealing treatment on FTIR spectra was also studied. The analysis of the spectra measured at Brewster incidence was performed because it gives more details on the evolution of FTIR spectra with annealing. As one can see from Fig. 2a, the shift of $\mathrm{Hf}-\mathrm{Si}-\mathrm{O}$ peak position (observed at about $1030 \mathrm{~cm}^{-1}$ for $\mathrm{AD}$ film) is more pronounced for the samples annealed at $T_{A} \geq 950{ }^{\circ} \mathrm{C}$, whereas lower annealing temperature does not affect this peak position. The increase of $t_{A}$ up to $15 \mathrm{~min}$ results in a pronounced shift of $\mathrm{Hf}-\mathrm{Si}-\mathrm{O}$ peak position to higher wavenumbers (Fig. 2a) as well as a significant increase of its intensity (Fig. 2b). This demonstrates that the main variation of FTIR spectra occurs at short-time treatment ( $\leq 15 \mathrm{~min}$ ) that is in agreement with the results of our earlier work [20]. At the same time, longer annealing time results in a slight shift of this peak (less than $2 \mathrm{~cm}^{-1}$ ) (Fig. 2a). The analysis of FTIR spectra shows also the decrease of intensity of $950-\mathrm{cm}^{-1}$ shoulder (considered as a contribution of the $\mathrm{HfSiO}_{x}$ phase) and its vanishing for $T_{A} \geq 1000{ }^{\circ} \mathrm{C}$. Along with this, the magnitude of $530 \mathrm{~cm}^{-1}$ band decreases, whereas the bands at $665 \mathrm{~cm}^{-1}$ and $770 \mathrm{~cm}^{-1}$ appear and increase in intensity (Fig. 2b). However, no significant variation of these peaks' positions was observed. This behavior of FTIR spectra means that there are two steps of the evolution of samples' microstructure. Short-time treatment results in the formation of $\mathrm{SiO}_{x}$ and $\mathrm{HfO}_{x}$ phases, whereas longer annealing causes the crystallization of $\mathrm{HfO}_{2}$ phase and further $\mathrm{SiO}_{x}$ decomposition. However, it is worth to note that the films annealed at $T_{A}=800-950{ }^{\circ} \mathrm{C}$, whatever $t_{A}$, demonstrate the $\mathrm{HfSiO}_{x}$ phase stability (Fig. 2a).

Raman scattering experiments of AD and annealed films were carried out to obtain additional information about microstructure evolution. For this purpose, the films deposited on $\mathrm{Si}$ and quarts substrates were investigated. Since corresponding Raman scattering spectra were found to be similar, hereafter we will discuss the spectra of the films grown on quarts wafers to eliminate the contribution of Si TO-phonon mode observed usually at $521 \mathrm{~cm}^{-1}$.

Fig. 3 shows only a broad band with a maximum at $\sim 499 \mathrm{~cm}^{-1}$ for AD samples. Upon annealing at $T_{A}=800{ }^{\circ} \mathrm{C}$, this peak position shifted up to $\sim 502 \mathrm{~cm}^{-1}$ (Fig. 3) that can be due to the formation of rather pure silicon phase than $\mathrm{HfO}_{2}$ phase. In fact, $\mathrm{HfO}_{2}$ related phonons are usually observed at $115 \mathrm{~cm}^{-1}, 295 \mathrm{~cm}^{-1}, 470 \mathrm{~cm}^{-1}$, $595 \mathrm{~cm}^{-1}$ and $665 \mathrm{~cm}^{-1}$ (for tetragonal phase) and at $123 \mathrm{~cm}^{-1}$. $146 \mathrm{~cm}^{-1}, 257 \mathrm{~cm}^{-1}, 316 \mathrm{~cm}^{-1}, 390 \mathrm{~cm}^{-1}, 496 \mathrm{~cm}^{-1}, 570 \mathrm{~cm}^{-1}$, $623 \mathrm{~cm}^{-1}$ and $660 \mathrm{~cm}^{-1}$ (for monoclinic phase) [22-26]. It is worth to note that the band peaked either at $470 \mathrm{~cm}^{-1}$ (tetragonal phase) or $498 \mathrm{~cm}^{-1}$ (monoclinic one) are the most intense phonon responses (Fig. 3). Since any formation of nanocrystalline or amorphous phase results in the broadening and low-energy shift of the phonons of bulk material, one can expect that nanocrystalline $\mathrm{HfO}_{2}$ phase have to follow this prediction [26,27]. Since the contribution of bulk $\mathrm{Si}$ TO phonon is eliminated, and $\mathrm{SiO}_{2}$ phonon is peaked at $\sim 495 \mathrm{~cm}^{-1}$ (Fig. 3) and the $\mathrm{HfO}_{2}$ related phonons are not observed at $500-525 \mathrm{~cm}^{-1}$, one can conclude that the peak observed at $502 \mathrm{~cm}^{-1}$ for the film annealed at $T_{A}=800{ }^{\circ} \mathrm{C}$ is due to $\mathrm{Si}$ TO phonon and attests for the formation of pure Si phase. Higher annealing temperatures result in a continuous shift of the Raman peak position up to $516 \mathrm{~cm}^{-1}\left(T_{A}=900{ }^{\circ} \mathrm{C}\right)$ as well as an increase of its intensity. This behavior can be ascribed to the formation of Si clusters as well as to the increase of their sizes and density. Their mean size was estimated to be 3.7-4.0 nm using the model described in Ref. [30].

Further $T_{A}$ increase up to $950-1100{ }^{\circ} \mathrm{C}$ results in the enhancement of Raman signal intensity as well as in the appearance of welldefined peaks at $455 \mathrm{~cm}^{-1}, 506 \mathrm{~cm}^{-1}, 523 \mathrm{~cm}^{-1}, 560 \mathrm{~cm}^{-1}$, $575 \mathrm{~cm}^{-1}$ and $625 \mathrm{~cm}^{-1}$. Higher $T_{A}$ values result in the enhancement 

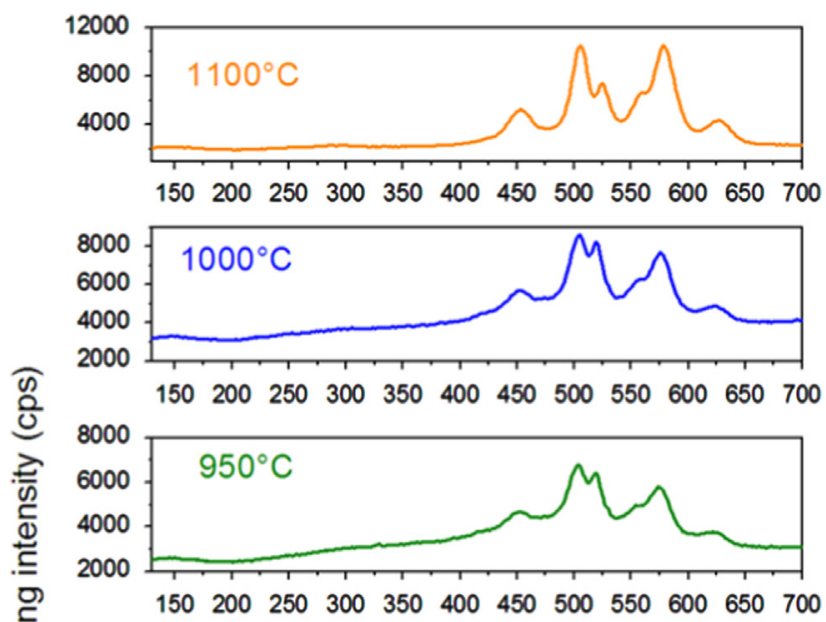

6000
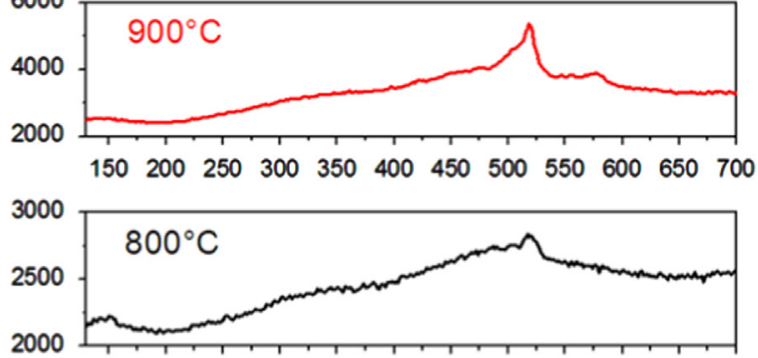

$\begin{array}{llllllllllll}150 & 200 & 250 & 300 & 350 & 400 & 450 & 500 & 550 & 600 & 650 & 700\end{array}$

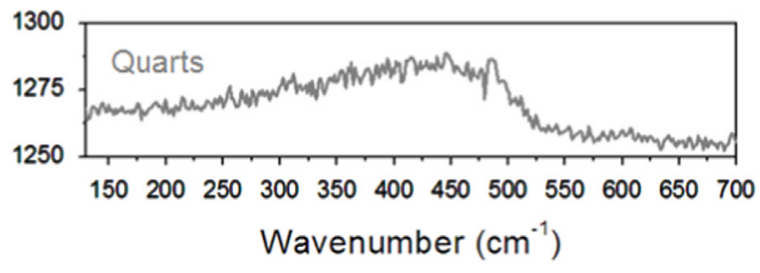

Fig. 3. Evolution of Raman scattering spectra of Si-rich $\mathrm{HfO}_{2}$ films with annealing temperature measured for the samples grown on quarts substrate. Corresponding spectrum for quartz substrate is presented for the comparison. The $T_{A}$ values are presented on the figure; $t_{A}=60 \mathrm{~min}$.

of all phonon modes as well as in the variation of their relative contribution to the spectrum (Fig. 3). All these bands correspond to the crystallized $\mathrm{HfO}_{2}$ phase, but some of them are overlapping with the Si TO phonon mode, hampering to conclude about the evolution of Si clusters' distribution (Fig. 3). To reveal the presence of $\mathrm{Si}$ clusters, cross-sections of annealed samples were observed by TEM.

Fig. 4 presents a high-resolution TEM image of the sample annealed at $T_{A}=950{ }^{\circ} \mathrm{C}$ and $t_{A}=60 \mathrm{~min}$ and showing the brightest PL emission. It is clearly seen some peculiarities of phase separation in the film volume. An irregular structure is observed in the film depth close to the film/substrate interface (Fig. 4, image 1). Dark grey regions are due to $\mathrm{HfO}_{2}$ phase, whereas white regions are due to $\mathrm{SiO}_{2}$, respectively. Light grey regions, separating both phases, can be due to either pure $\mathrm{Si}$ phase $\left(\right.$ or $\mathrm{SiO}_{x}$ phase with high $\mathrm{Si}$ content), or $\mathrm{HfSiO}_{x}$ phase, considering the relatively large volume of this phase. The structure in the middle part of the film (image 3 ) appears to be unaffected by the thermal treatment. This can explain the significant contribution of $\mathrm{Hf}-\mathrm{Si}-\mathrm{O}$ vibration bands in FTIR spectra of samples annealed at $T_{A}=950{ }^{\circ} \mathrm{C}$ (Figs. 1 and 2). The cross-section of upper regions showed the formation of alternated layers with different contrasts that can be related to the formation of Hf-rich and Si-rich layers (Fig. 4, image 4). Observed features of the structure can be explained taking into account the possible mechanism of $\mathrm{HfSiO}_{x}$ decomposition.

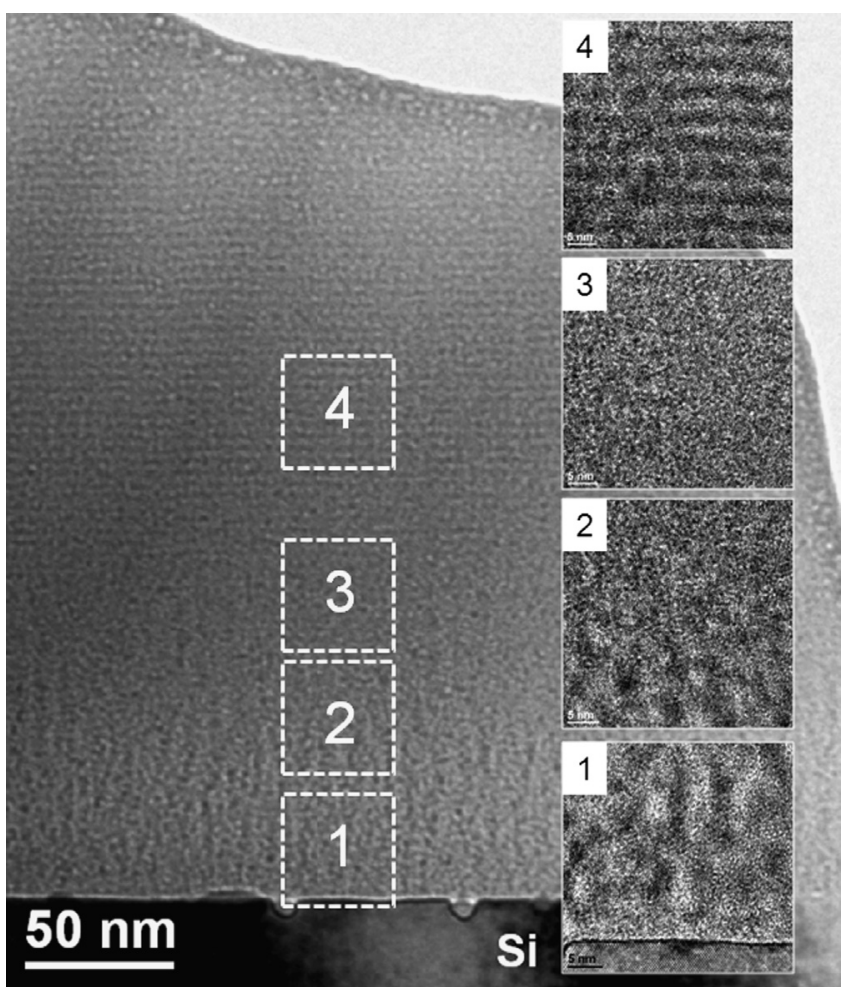

Fig. 4. Cross-sectional bright-field TEM images of the sample annealed at $900{ }^{\circ} \mathrm{C}$ The images 1-4 represent magnified sections of different regions of the film depth.

Several mechanisms are known to explain the processes of material decomposition. One of them is Ostwald ripening that described the change of an inhomogeneous structure over time, when some clusters (grains) grow, only to be later dissolved, and other clusters are increasing in size due to the diffusion of corresponding species [31]. However, the initial formation of the microscopic clusters involves a large free energy barrier, and so can be very slow. Contrary to Ostwald ripening, spinodal decomposition is the mechanism for the rapid unmixing of a mixture of liquids or solids from one thermodynamic phase [32,33]. A clustering reaction occurs in a homogeneous, supersaturated solid solution, which is unstable against infinitesimal fluctuations in density or composition. This solution therefore separates spontaneously into two phases, starting with small fluctuations and proceeding with a decrease in the Gibbs energy without a nucleation barrier [32,33]. It is known that $\mathrm{HfSiO}_{x}$ materials have a metastable miscibility gap due to the covalent nature of $\mathrm{Si}-\mathrm{O}$ bonds on one hand and ionic nature of $\mathrm{Hf}-\mathrm{O}$ ones, on the other hand. The decrease of film free energy occurs usually through a phase separation process between $\mathrm{HfO}_{2}$-rich and $\mathrm{SiO}_{2}$-rich phases [34] when the $\mathrm{HfO}_{2}$ phase forms at first. Thus, Ostwald ripening could not explain the formation of alternated multilayer structure in our films. At the same time, spinodal decomposition supposes the existence of compositional wavelength, $\lambda_{C}$, in the mixture, causes multilayer formation. This $\lambda_{C}$ value, can be defined as an average distance between the centres of two successive $\mathrm{HfO}_{2}$ rich layers [34] and for our films $\lambda_{C}$ was found to be about 4-5 nm.

For very thick films (compared to bulk materials), this composition wave starts to form at their surface and decays towards the volume. However, the substrate/film interface stimulates also formation of composition wave. Thus, the interaction of the waves penetrating in opposite directions, i.e. from film/substrate interface towards film surface and vice versa [34], will determine the result of the phase separation. The formation of alternated layer structure close to the film surface is an evidence of significant role of the surface in the phase separation process. 
Besides $\mathrm{HfO}_{2}$ and $\mathrm{SiO}_{2}$ phases, light grey regions separating the two phases were also observed (Fig. 4, images 1,2). They can correspond to either pure $\mathrm{Si}$ phase (or $\mathrm{SiO}_{x}$ phase with low amount of oxygen), or $\mathrm{HfSiO}_{x}$ phase, considering the relatively large volume of this phase. From the comparison of FTIR (Figs. 1 and 2) and Raman scattering data (Fig. 3), one can suppose that the contribution of silicon-rich phase exceeds that of $\mathrm{HfSiO}_{x}$. It is interesting to notice that the diameters of light-grey regions do not exceed $5 \mathrm{~nm}$ (Fig. 4). This is in agreement with Si-ncs mean size estimated from Raman scattering spectra (Fig. 3). However, any sequences of crystalline planes were not revealed during TEMHREM observation. The amorphous nature was also confirmed by selected angle electron diffraction data (not shown here).

One of the reasons could be a non-completed phase separation process. In this case, not only the $\mathrm{HfO}_{2}$ and $\mathrm{SiO}_{2}$ phases are formed, but also $\mathrm{SiO}_{x}$ (with a high $\mathrm{Si}$ content). Besides $\mathrm{HfSiO}_{x}$ is observed and found to be stable at $900-950{ }^{\circ} \mathrm{C}$ (Fig. 2). It is clear that $T_{A}=950{ }^{\circ} \mathrm{C}$ can be too low to stimulate the crystallization of Si-rich phase. This fact is in agreement with the Raman scattering data showing peak position of TO Si phonon mode at about $516 \mathrm{~cm}^{-1}$ instead of $521 \mathrm{~cm}^{-1}$ for crystallized Si phase (Fig. 3). The presence of amorphous Si clusters was also demonstrates by atomic-probe tomography study for similar samples [35].

The increase of the annealing temperature up to $1000{ }^{\circ} \mathrm{C}$ results mainly in the crystallization of $\mathrm{HfO}_{2}$-rich phase and in the formation of $\mathrm{HfO}_{2}$ nanocrystals. Besides, the crystallization of $\mathrm{Si}$ clusters occurs [36]. However, this process starts at $1000-1050{ }^{\circ} \mathrm{C}$ [33] before the temperatures usually required for the formation of Si-ncs in $\mathrm{SiO}_{2}$ host $\left(1100-1150{ }^{\circ} \mathrm{C}\right)[3,14,37,38]$.

It is known that formation of Si-ncs results in a bright visible PL emission $[3,14,38]$. Along with this, the peak position of corresponding PL band demonstrates usually the "blue" shift with the size decrease $[3,38]$. By analogy, the similar behavior of PL emission from Si clusters embedded in $\mathrm{HfO}_{2}$ can be also expected. Thus, the comparison of light emitting properties of Si-rich- $\mathrm{HfO}_{2}$ samples with that of $\mathrm{Si}-$ rich- $-\mathrm{SiO}_{2}$ films, grown with similar approach $[3,38]$, can give information about the formation of $\mathrm{Si}$ clusters in $\mathrm{HfO}_{2}$-based host.

\subsection{Light emission from the films}

AD samples showed blue PL emission under UV (260-360 nm) excitation only [17]. Any luminescence was not detected under visible
(450-535 nm) excitation. Annealing treatments at $T_{A}>800{ }^{\circ} \mathrm{C}$ result in the appearance of PL emission in the red spectral range (Fig. 5a). It is worth to note that we used $532-\mathrm{nm}$ excitation to separate the contribution from host defects and formed Si clusters.

The comparison of pure $\mathrm{SiO}_{2}$, pure $\mathrm{HfO}_{2}, \mathrm{Si}$-rich- $\mathrm{SiO}_{2}$ and $\mathrm{Si}-$ rich $\mathrm{HfO}_{2}$ films (Fig. 5a) showed that this red emission is due to $\mathrm{Si}$ cluster formation. Their presence was also predicted by Raman scatting spectra (Fig. 3). Red emission was found to be very similar to the case of Si-rich-SiO ${ }_{2}$ materials (Fig. 5a) and can be thus attributed to $\mathrm{Si}$ clusters formed in $\mathrm{Si}$-rich- $\mathrm{HfO}_{2}$ samples upon annealing treatment. The peak position of this PL band shifts to shorter wavelengths (from $820 \mathrm{~nm}$ to $690 \mathrm{~nm}$ ) with $T_{A}$ increase from $850{ }^{\circ} \mathrm{C}$ to $1100{ }^{\circ} \mathrm{C}$ at constant $t_{A}$ (Fig. 5b). This can be ascribed to the decrease of mean size of $\mathrm{Si}$ clusters. The $t_{A}$ increase at constant $T_{A}$ results in the shift of PL peak position to longer wavelengths [17] that can be caused by an increase of Si cluster sizes similar to the case observed for $\mathrm{Si}$-rich $\mathrm{SiO}_{2}$ films $[3,38]$. The PL intensity shows a non-monotonous behavior (Fig. 5b). The most efficient emission was detected for samples annealed at $T_{A}=900-$ $950{ }^{\circ} \mathrm{C}, t_{\mathrm{A}}=60 \mathrm{~min}$.

It is known that $\mathrm{Si}$ clusters embedded in $\mathrm{SiO}_{2}$ host doped with rare-earth ions are effective sensitizers of these latter [12-14]. Thus, an achievement of the efficient PL emission from rare-earth elements under non-resonant excitation can be an additional argument of $\mathrm{Si}$-ncs presence in $\mathrm{HfO}_{2}$ host. For this purpose, pure and Si-rich $\mathrm{HfO}_{2}$ films were co-doped with $\mathrm{Er}^{3+}$ ions and their PL properties have been studied versus annealing treatment.

Among usually addressed $\mathrm{Er}^{3+}$ emission in $1.4-1.7 \mu \mathrm{m}$ from ${ }^{4} \mathrm{I}_{13 / 2} \rightarrow{ }^{4} \mathrm{I}_{15 / 2}$ transitions, the spectra were recorded in the 630700 -nm range corresponding to ${ }^{4} \mathrm{~F}_{9 / 2} \rightarrow{ }^{4} \mathrm{I}_{15 / 2}$ transitions at resonant (488 nm or $532 \mathrm{~nm}$ ) and non-resonant (476 nm) excitations.

Fig. 6 shows a comparison of PL spectra of $\mathrm{Er}^{3+}$-doped and $\left(\mathrm{Er}^{3+}, \mathrm{Si}\right)$-codoped $\mathrm{HfO}_{2}$ films annealed at $T_{A}=900{ }^{\circ} \mathrm{C}, t_{A}=60 \mathrm{~min}$. Since pure $\mathrm{HfO}_{2}$ does not emit under 532-nm excitation wavelength (Fig. 6), this means that, if any oxygen vacancies are present in Er-doped $\mathrm{HfO}_{2}$ films, their emission cannot be excited by this light wavelength. Moreover, self-trapped excitons, requiring an ultraviolet excitation [6], are not considered as a sensitizer of $\mathrm{Er}^{3+}$ ions, since used optical excitation is not efficient in this case. Thus, well-defined PL peaks (corresponding to ${ }^{4} \mathrm{~F}_{9 / 2} \rightarrow{ }^{4} \mathrm{I}_{15 / 2}$ ) observed for Er-doped $\mathrm{HfO}_{2}$ films under 532-nm excitations (Fig. 6) are due to direct excitation of $\mathrm{Er}^{3+}$ ions. This latter was confirmed by very low PL intensity (as a noise level) observed under "non-resonant" 476-nm-illumination [17]. a

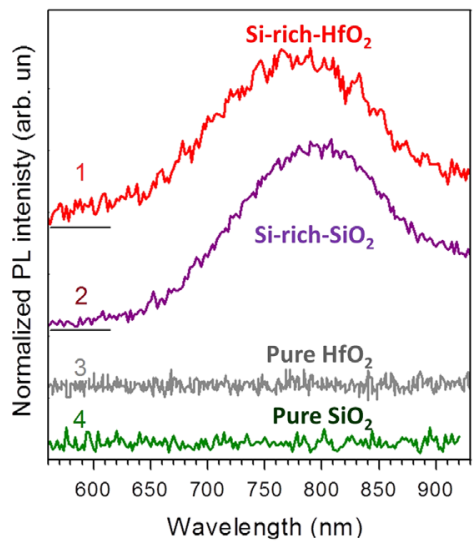

$b$

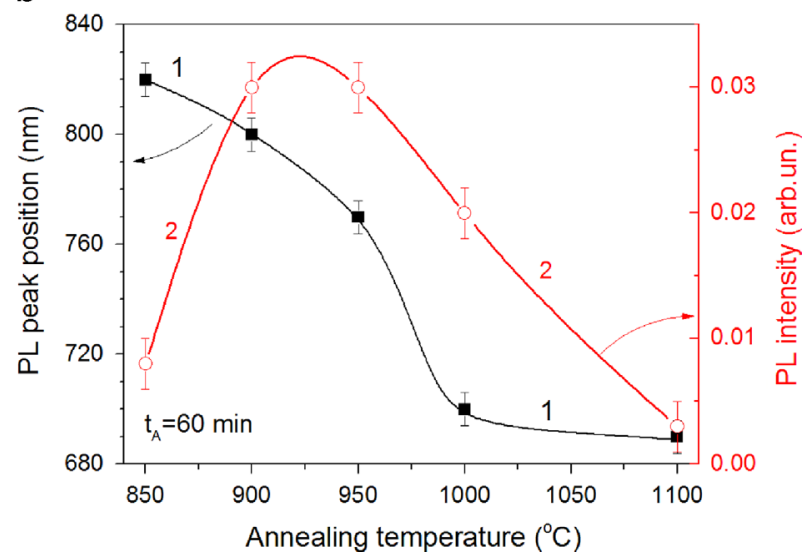

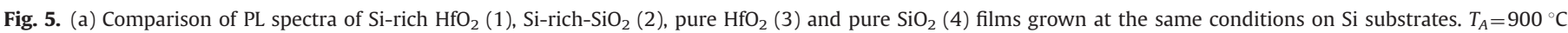

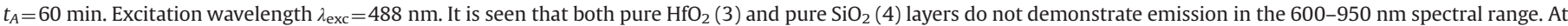

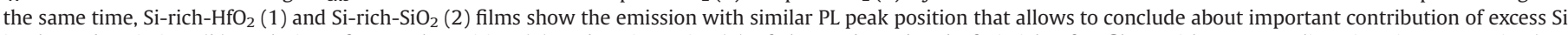

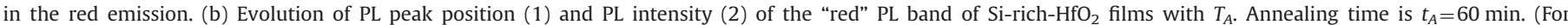
interpretation of the references to color in this figure legend, the reader is referred to the web version of this article.) 


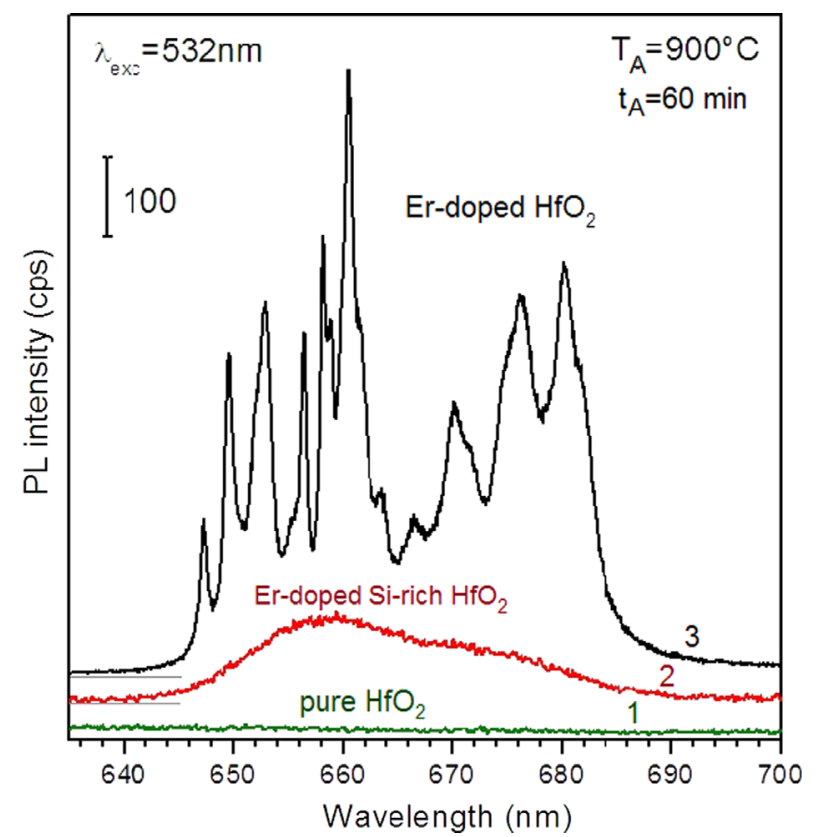

Fig. 6. PL spectra of pure $\mathrm{HfO}_{2}(1)$, Er-doped $\mathrm{HfO}_{2}$ (2) and Er-doped Si-rich-HfO (3) films grown with the same conditions on Si substrate and annealed at $T_{A}=900{ }^{\circ} \mathrm{C}$ and $t_{A}=60 \mathrm{~min}$. The spectra were measured under excitation with $\lambda_{\text {exc }}=532 \mathrm{~nm}$.

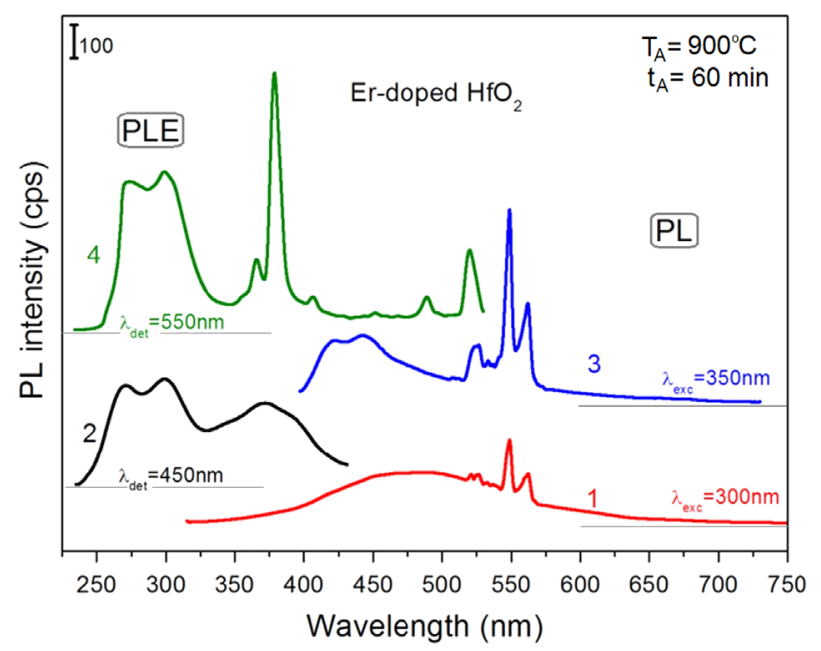

Fig. 7. $\mathrm{PL}(1,3)$ and $\mathrm{PLE}(2,4)$ spectra of Er-doped $\mathrm{HfO}_{2}$ samples annealed $T_{A}=900{ }^{\circ} \mathrm{C}$ and $t_{A}=60 \mathrm{~min}$. PL spectra were measured under excitation with $\lambda_{\mathrm{exc}}=300$ (1) and $350 \mathrm{~nm}$ (3). PLE spectra were detected at $\lambda_{\mathrm{det}}=450$ (2) and $550 \mathrm{~nm}$ (4). The spectra are shifted in vertical direction for clarity. (For interpretation of the references to color in this figure legend, the reader is referred to the web version of this article.)

Fig. 7 presents PL spectra of Er-doped $\mathrm{HfO}_{2}$ films under UV excitation (curves 1,3) and corresponding PLE spectra (curves 2,4). Several broad PLE bands are seen at $280 \mathrm{~nm}(4.42 \mathrm{eV}), 300 \mathrm{~nm}$ $(4.13 \mathrm{eV})$ and $370 \mathrm{~nm}(3.30 \mathrm{eV})$, when detected at $\lambda_{\mathrm{det}}=450 \mathrm{~nm}$ (Fig. 7, curve 2). The overlapping of all these bands can affect their peak positions and a slight shift of their maxima can be observed. Two first peaks are usually ascribed to negatively charged Hfrelated oxygen vacancies with different coordination, i.e. $V_{O(3)}^{-2}$ $(4.42-4.44 \mathrm{eV})$ and $\mathrm{V}_{O(4)}^{-2}(4.2-4.23 \mathrm{eV})$ [36]. The third PLE band can be attributed to either neutral or positively charge oxygen vacancies, i.e. $\mathrm{V}_{O(3)}^{0}$ or $\mathrm{V}_{O(3)}^{+2}$ based on the data of Ref. [39].

The broad PL band peaked at $400-460 \mathrm{~nm}$ is due to the relaxation of the vacancies (Fig. 7 , curves 1,3). It results in the blue light emission under UV light excitation. Sharp peaks in the 520-570 nm range (Fig. 7, curve 3 ) are caused by ${ }^{4} \mathrm{~S}_{3 / 2} \rightarrow{ }^{4} \mathrm{I}_{15 / 2}$ transitions in $\mathrm{Er}^{3+}$ ions that is confirmed by the PLE spectrum recorded at $\lambda_{\text {det }}=550 \mathrm{~nm}$, showing the corresponding sharp excitation lines (Fig. 7, curve 4). The PLE spectrum detected at $\lambda_{\text {det }}=450 \mathrm{~nm}$ (curve 2) has broad PLE bands with maxima at $280 \mathrm{~nm}$ and $300 \mathrm{~nm}$, whereas the peak at about $380 \mathrm{~nm}$ is overlapped with the absorption bands corresponded to ${ }^{4} \mathrm{I}_{15 / 2} \rightarrow{ }^{4} \mathrm{G}_{11 / 2}$, ${ }^{4} \mathrm{H}_{11 / 2}$ transitions in $\mathrm{Er}^{3+}$ ions. Thus, one can conclude that, using UV-blue light, $\mathrm{Er}^{3+}$ ions can be effectively excited not only via direct excitation but also via an efficient energy transfer from oxygen vacancies in the $\mathrm{HfO}_{2}$ matrix.

Similar host mediate excitation was observed for Er-doped Sirich- $\mathrm{HfO}_{2}$ samples. Fig. 8 shows the comparison of PL and PLE spectra obtained for Er-free (curves 1,5) and Er-doped films (curves 2-4,3-6). The variation of the excitation wavelength in the 260-380 nm spectral range does not result in a shift of the PL peak position. Thus, this PL band is most probable due to defects in the Si-rich- $\mathrm{HfO}_{2}$ matrix.

In general, PLE spectra of all the samples are broad. Two main peaks are observed similar to those of Er-free Si-rich- $\mathrm{HfO}_{2}$ samples (Fig. 8). The first one is situated at about $290 \mathrm{~nm}(4.27 \mathrm{eV})$, whereas the position of the second peak depends on the detection wavelength. Meanwhile, it is observed between $370 \mathrm{~nm}$ and $400 \mathrm{~nm}$ (3.35-3.10 eV). Similar shift of PLE peak position was reported in Ref. [38] and explained by a depth distribution of the emitting defects. It is interesting that the Er-free samples show broader PL spectrum (Fig. 8, curve 1) than their Er-doped counterparts (curves, 2-4). This can be due to quenching of some radiative channels transferring efficiently their energy towards $\mathrm{Er}^{3+}$ ions. This assumption is supported by the observation of some PL peaks in the green $(\sim 570 \mathrm{~nm})$ and orange $(\sim 620 \mathrm{~nm})$ spectral ranges (Fig. 8, curves 2-4) when 260-280 nm-excitation is used. The PLE spectrum, measured at $\lambda_{\mathrm{det}}=615$-nm wavelength (Fig. 8 , curve 8 ), confirms the $\mathrm{Er}^{3+}$ origin of the green and orange emissions.

It is interesting to note that PLE spectrum, measured at $\lambda_{\text {det }}=720 \mathrm{~nm}$ (corresponding to PL maximum of Si cluster's emission [17]), was found to be similar to the spectrum detected at $\lambda_{\text {det }}=650$ (Fig. 8, curve 6). The same data were obtained in Ref. [40] demonstrating that oxygen-related defects can take part in the excitation of $\mathrm{Si}$ clusters in $\mathrm{Si}-\mathrm{rich}-\mathrm{SiO}_{2}$ films.

PL study of Er-doped Si-rich- $\mathrm{ZrO}_{2}$ films [41,42] revealed the $\mathrm{Er}^{3+}$ emission under non-resonant excitation and ascribed it to an energy transfer from Si clusters. However, the presence of these latter was not clearly demonstrated. Meanwhile, it was shown that oxygen-deficient silicon centers (Si-ODCs) and oxygen interstitial defects are effective excitation paths for $\mathrm{Er}^{3+}$ ions [40]. It is also known that Si- (Ge-)ODCs can be effective sensitizers of rare earth ions embedded in Si-rich [40] or Ge-rich [43] silicon oxide host.

Thus, one can conclude that the energetic balance of interacting "Er-ions, Si clusters and defects" system is complicated. All three of them can emit light under "corresponding" excitation, whereas Si clusters and defects can be effective sensitizers for rare-earth ions. This can allow achieving broad-band emission from hafniumsilicates doped by other rare earth ions.

\section{Conclusions}

In the present study, the properties of RF magnetron sputtered hafnium silicate films were investigated by means of FTIR, Raman scattering, TEM, PL and PLE methods. It was observed that high temperature annealing governs a phase separation process as well as the formation of silica, hafnia and silicon phases. The appearance of a PL emission in the visible-near-infrared spectral range occurred. The evolution of the PL peak position was found to be correlated to the Si-ncs size. The properties of Si-doped- $\mathrm{HfO}_{2}$ films 


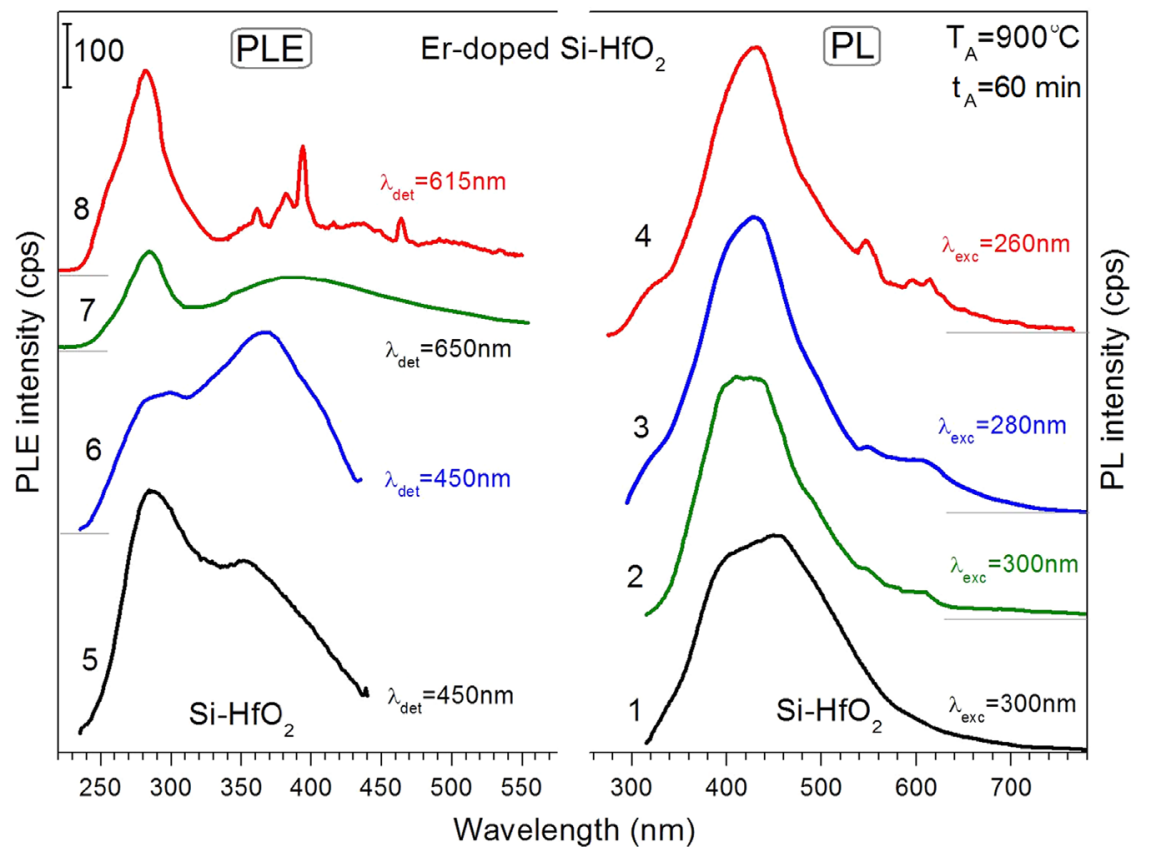

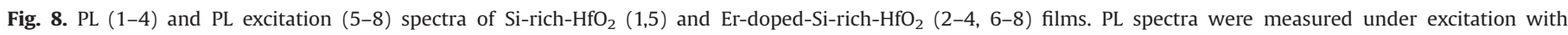

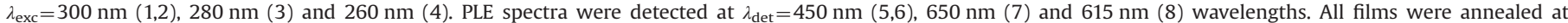

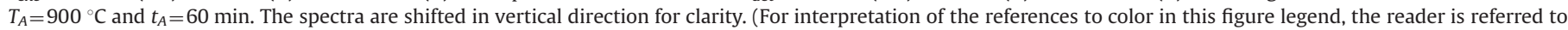
the web version of this article.)

are compared to those of their counterparts doped with $\mathrm{Er}^{3+}$ ions. The investigation of the effect of annealing treatment on luminescent properties revealed that the enhancement of $\mathrm{Er}^{3+}$ PL emission occurs due to an effective energy transfer from Si-nanoclusters and defects of hafnia based host (such as oxygen vacancies).

\section{Acknowledgments}

This work was partially supported by the French National Agency (ANR) through Nanoscience, Nanotechnology Program (NOMAD project, No. ANR-07-NANO-022-02) and the Conseil Regional de Basse Normandie through the CPER project of the program "Nanoscience axe" (2007-2013), as well as by the National Academy of Sciences of Ukraine (project III-4-11).

\section{References}

[1] G. He, L.Q. Zhu, Z.Q. Sun, Q. Wan, L.D. Zhang, Prog. Mater. Sci. 56 (2011) 475.

[2] L. Khomenkova, X. Portier, J. Cardin, F. Gourbilleau, Nanotechnology 21 (2010) 285707.

[3] L. Khomenkova, B.S. Sahu, A. Slaoui, F. Gourbilleau, Nanoscale Res. Lett. 6 (2011) 172.

[4] J.M. Khoshman, A. Khan, M.E. Kordesch, Surf. Coat. Technol. 202 (2008) 2500.

[5] O. Stenzel, S. Wilbrandt, S. Yulin, N. Kaiser, M. Held, A. Tünnermann, J. Biskupek, U. Kaiser, Opt. Mater. Express 1 (2011) 278

[6] M. Kirm, J. Aarik, M. Jürgens, I. Sildos, Nucl. Instr. Meth. A 537 (2005) 251.

[7] K. Smits, L. Grigorjeva, D. Millers, A. Sarakovskis, J. Grabis, W. Lojkowski, J. Lumin. 131 (2011) 2058.

[8] V. Kiisk, I. Sildos, S. Lange, V. Reedo, T. Tatte, M. Kirm, J. Aarik, Appl. Surf. Sci. 247 (2005) 412.

[9] L.X. Liu, Z.W. Ma, Y.Z. Xie, Y.R. Su, H.T. Zhao, M. Zhou, J.Y. Zhou, J. Li, E.Q. Xie, J. Appl. Phys. 107 (2010) 024309.

[10] C. Stoneman, L. Esterowitz, Opt. Lett. 15 (1990) 486

[11] L. Feng, J. Wang, Q. Tang, L.F. Liang, H.B. Liang, Q. Su, J. Lumin. 124 (2007) 187.

[12] A.J. Kenyon, Semicond. Sci. Technol. 20 (2005) R65.

[13] M. Wojdak, M. Klik, M. Forcales, O.B. Gusev, T. Gregorkiewicz, D. Pacifici, G. Franzò, F. Priolo, F. Iacona, Phys. Rev. B 69 (2004) 233315.

[14] S. Cueff, C. Labbé, J. Cardin, J.-L. Doualan, L. Khomenkova, K. Hijazi, O. Jambois, B. Garrido, R. Rizk, J. Appl. Phys. 108 (2010) 064302.

[15] J. Miniscalco, J. Lightwave Technol. 9 (1991) 234.
[16] G.C. Righini, S. Berneschi, G. Nunzi Conti, S. Pelli, E. Moser, R. Retoux, P. Féron, R.R. Gonçalves, G. Speranza, Y. Jestin, M. Ferrari, A. Chiasera, A. Chiappini, C. Armellini., J. Non-Cryst. Solids 355 (2009) 1853.

[17] L. Khomenkova, Y.-T. An, C. Labbé, X. Portier, F. Gourbilleaua, ECS Trans. 45 (2012) 119.

[18] N.V. Nguyen, A.V. Davydov, D. Chandler-Horowitz, M.F. Frank, Appl. Phys. Lett. 87 (2005) 192903.

[19] M.M. Frank, S. Sayan, S. Dörmann, T.J. Emge, L.S. Wielunski, E. Garfunkel, Y.J. Chabal, Mater. Sci. Eng., B 109 (2004) 6.

[20] L. Khomenkova, C. Dufour, P.-E. Coulon, C. Bonafos, F. Gourbilleau, Nanotechnology 21 (2010) 0955704.

[21] M. Lui, L.Q. Zhu, G. He, Z.M. Wang, J.X. Wu, J.-Y. Zhang, I. Liaw, Q. Fang, I.W. Boyd, Appl. Surf. Sci. 253 (2007) 7869.

[22] B.-K. Kim, H.-O. Hamaguchi, Mater. Res. Bull. 32 (1997) 1367.

[23] A.C. Marques, R.M. Almeida, J. Sol-Gel Sci. Technol. 40 (2006) 371.

[24] M. Yashima, H. Takahashi, K. Ohtake, T. Hirose, M. Kakihana, H. Arashi Y. Ikuma, Y. Suzuki, M. Yoshimura, J. Phys. Chem. Solids 57 (1996) 289.

[25] X. Zhao, D. Vanderbilt, Phys. Rev. B 65 (2002) 233106.

[26] H. Arashi, J. Am. Ceram. Soc. 75 (1992) 844.

[27] M. Mattarelli, M. Montagna, F. Rossi, C. Tosello, N.D. Afify, M. Bettinelli, A. Speghini, C. Armellini, Y. Jestin, F. Rocca, S. Gialanella, Opt. Mater. 31 (2009) 1362.

[28] C.T. Kirk, Phys. Rev. B 38 (1988) 1255.

[29] P. Lange, J. Appl. Phys. 66 (1989) 201.

[30] H. Richter, Z.P. Wang, L. Ley, Solid State Commun. 39 (1981) 625

[31] I.M. Lifshitz, V.V. Slyozov, J. Phys. Chem. Solids 19 (1961) 35.

[32] J.W. Cahn, Acta Metall. 9 (1961) 795.

[33] V.P. Skripov, A.V. Skripov, Sov. Phys. Usp. 22 (1979) 389.

[34] J. Lui, X. Wu, W.N. Lennard, D. Landheer, M.N.C. Dharma-Wardana, J. Appl Phys. 107 (2010) 123510.

[35] E. Talbot, M. Roussel, L. Khomenkova, F. Gourbilleau, P. Pareige, Mater. Sci Eng., B 177 (2012) 717.

[36] Y.-T. An, C. Labbé, L. Khomenkova, M. Morales, X. Portier, F. Gourbilleau, Nanoscale Res. Lett. 8 (2013) 43.

[37] E. Talbot, R. Lardé, F. Gourbilleau, C. Dufour, P. Pareige., Eur. Phys. Lett. 87 (2009) 26004

[38] L. Khomenkova, N. Korsunska, V. Yukhimchuk, B. Jumayev, T. Torchynska, A. Vivas Hernandez, A. Many, Y. Goldstein, E. Savir, J. Jedrzejewski., J. Lumin. 102-103 (2003) 705.

[39] H.-K. Noh, B. Ruy, E.-A. Choi, J. Bang, K.J. Chang, Appl. Phys. Lett. 95 (2009) 082905.

[40] S. Cueff, C. Labbé, B. Dierre, F. Fabbri, T. Sekiguchi, X. Portier, R. Rizk, J. Appl. Phys. 108 (2011) 113504.

[41] C. Rozo, L.F. Fonseca, J. Phys.: Condens. Matter 20 (2008) 315003.

[42] C. Rozo, D. Jaque, L.F. Fonseca, J.G. Solé, J. Lumin. 128 (2008) 1197.

[43] A. Kanjilal, L. Rebohle, M. Voelskow, W. Skorupa, M. Helm, Appl. Phys. Lett. 94 (2009) 051903. 